\title{
Estágio de Neonatologia na Graduação de Enfermagem: enfrentamentos e desafios num contexto de mudanças
}

\author{
Clinical practice in Neonatology during Undergraduate Nursing course: \\ coping and challenges in a context of changes \\ Práctica clínica en Neonatología en la Graduación de Enfermería: \\ enfrentamientos y desafíos en un contexto de cambios
}

\section{Elaine Rodrigues Gesteira', Paulete Goldenberg"}

'Universidade Federal de São João Del Rei, Campus Centro-Oeste, Curso de Enfermagem, Divinópolis-MG, Brasil.

"Universidade Federal de São Paulo, Departamento de Medicina Preventiva, Programa de Pós-Graduação de Saúde Coletiva; Centro de Desenvolvimento do Ensino Superior em Saúde, Programa de Pós-Graduação de Ensino em Ciências da Saúde. São Paulo-SP, Brasil.

Submissão 29-07-2010 Aprovação:01-03-2012

\section{RESUMO}

Este trabalho objetivou analisar o diagnóstico situacional do estágio de Enfermagem na área de Neonatologia em distintas instituições de ensino superior na cidade de São Paulo, a fim de identificar os desafios em relação às novas exigências educacionais. A pesquisa, de cunho exploratório e com abordagem qualitativa, envolveu a caracterização do estágio no plano institucional e seu dimensionamento na perspectiva dos alunos. Conforme apontam os resultados, junto à programação convencional, ter, ou não, campo próprio para o estágio constituiu diferencial significativo no seu desenvolvimento. A formação generalista, na forma como é concebida, coexiste com a aspiração pela especialização. Os alunos reivindicam maior aproximação aos recémnascidos de alto risco. Conclui-se que há necessidade de repensar essas questões no âmbito da Graduação.

Descritores: Enfermagem neonatal; Ensino; Estudante de enfermagem; Currículo.

\section{ABSTRACT}

This work aimed to analyze the situational diagnosis of the Undergraduate Nursing clinical practice in the field of Neonatology in different institutions of higher education in the city of São Paulo, Brazil, in order to identify the challenges with regard to the new educational requirements. The research, with an exploratory design and a qualitative approach, concerned the characterization of the clinical practice in the institutional sphere and its dimensioning from the perspective of students. According to the results, along with the conventional planning, having or not a proper environment for training constitutes a significant difference in its development. The generalist clinical practice, as it is now conceived, coexists with the desire for specialization. Students ask for a closer contact to the high-risk newborn infants. One concludes that there's a need for rethinking these issues within the Undergraduate Nursing course.

Key words: Neonatal nursing; Teaching; Nursing student; Curriculum.

\section{RESUMEN}

Este trabajo objetivó analizar el diagnóstico situacional de la práctica clínica de Enfermería en el área de Neonatología en diferentes instituciones de enseñanza superior en la ciudad de São Paulo, Brasil, a fin de identificar los desafíos con relación a las nuevas exigencias educacionales. La investigación, de naturaleza exploratoria y con abordaje cualitativo, envolvió la caracterización de la práctica clínica en el plano institucional y su dimensionamiento en la perspectiva de los alumnos. Como apuntan los resultados, junto con la programación convencional, tener o no campo propio para la práctica constituyó diferencial significativo en su desarrollo. La formación generalista, en la manera como es concebida, coexiste con la aspiración por la especialización. Los alumnos reivindican una mayor aproximación a los recién nacidos de alto riesgo. Se concluye que hay necesidad de repensar esas cuestiones en el ámbito de la Graduación en Enfermería.

Palabras clave: Enfermería neonatal; Enseñanza; Estudiantes de enfermería; Currículo. 


\section{INTRODUÇÃO}

A Enfermagem, ao longo de sua trajetória, registra a consolidação das práticas ancoradas no conhecimento científico em detrimento das práticas leigas, destacando-se, nesse percurso, a necessidade da capacitação de nível superior. Sob influência do Relatório Flexner, é preconizada a formação científica, para além do convencional treinamento profissionalizante - $\mathrm{O}$ que fundamenta, juntamente com a constituição dos ciclos básico e profissionalizante, recortados pelas disciplinas, a configuração do modelo sequencial da relação entre a teoria e prática ${ }^{(1)}$. Nesse contexto, é reservado ao estágio o papel estratégico de um laboratório de práticas.

A aprovação da Lei de Diretrizes e Bases da Educação Nacional $^{(2)}$ demarcou a estruturação do ensino em âmbito nacional, sendo preconizada a composição do currículo mínimo pelo Conselho Federal de Educação (CFE). Nesse conjunto, a última série da Graduação em Enfermagem passou a comportar as Especializações em Saúde Pública e Obstetrícia. O curso passou de 2.430 horas para 3.240 horas, ficando regulamentado o espaço de $10 \%$ da carga horária para os estágios ${ }^{(3)}$.

No contexto da renovação desenvolvimentista do Estado, instalou-se a Reforma Universitária em 1968. Vislumbrando o desenvolvimento da pesquisa e a formação de especialistas, estruturou-se, junto ao projeto de renovação econômica, a atenção materno-infantil, estratégica para a reposição da força de trabalho ${ }^{(4)}$. Na época, a Neonatologia se estruturou como um campo de conhecimento específico, sendo possível, diante dos progressivos avanços tecnológicos, assistir aos casos de alto risco em âmbito hospitalar.

A incorporação da Sistematização da Assistência de Enfermagem (SAE), fundamentada na Teoria das Necessidades Básicas, demarcou a formalização do campo específico da Enfermagem $^{(3)}$. Diante das lutas da categoria, a Lei $n^{\circ}$ 163/72 definiu as atribuições do enfermeiro, explicitando-se as incumbências administrativas no âmbito das atividades assistenciais, ao lado do ensino e da pesquisa - anunciando transformações já em curso(5).

Reatualizando a composição curricular anterior, as especialidades (Parecer n. 163/72) foram substituídas pelas habilitações em Enfermagem Médico-Cirúrgica, Obstétrica e de Saúde Pública, reservando-se uma carga horária "não inferior a um terço das partes profissionais para os estágios na Graduação, o que significou uma conquista para a formação profissional"(5).

Se esses avanços demarcam indagações em relação ao desenvolvimento dos estágios de Neonatologia, considerando que não constituem, necessariamente, um campo disciplinar autônomo na estrutura curricular, ressaltam-se os desafios de sua concretização diante da necessidade de readaptação às mudanças que se descortinam no âmbito da assistência e do ensino no país.

Por volta dos anos 1980, registrou-se o crescimento dos cursos de graduação e de pós-graduação no país, paralelamente à valorização das especializações ${ }^{(6)}$. Se o desenvolvimento do sistema previdenciário propiciou a expansão da assistência individualizada - que alimentou a especialização - a reorganização da assistência que culminou na aprovação do Sistema
Único de Saúde (SUS) em 1988, demarcou um movimento no contrafluxo dessas tendências. Ao preconizar a formação generalista, a nova disposição incidiu sobre a necessidade de repensar o ensino, ressaltando-se a superposição dessa problemática à tradicional cisão entre a teoria e a prática.

Envolvendo o trato com a família e a comunidade, em situações reais de atendimento, o treinamento do enfermeiro na atenção ao recém-nascido (RN) passa a comportar uma diversificação do campo de estágio, tradicionalmente circunscrito ao espaço hospitalar. Nessas condições se situa o desafio de propiciar a integração de conhecimentos e vivências na esfera de um currículo estruturado de forma disciplinar, fragmentada e especializante.

No âmbito educacional, o desenvolvimento ancorado na ciência, informação e nos meios de comunicação acaba por incidir na reordenação da própria formação profissional. Dessa maneira, há a necessidade de buscar "novas formas de acessar e sistematizar o conhecimento, com a emergência do aprendizado em contexto, em redes sociais e em múltiplas fontes de experiência"(7). Tais desafios comportam um movimento de reconsideração das práticas tradicionais de ensino/ aprendizagem. Desloca-se o foco do ensino transmissivo centrado no professor para o ensino centrado no aluno, destaca-se a atuação na construção da aprendizagem significativa ${ }^{(8)}$. Essas novas disposições se inscrevem na Lei de Diretrizes e Bases da Educação ${ }^{(9)}$, que renova a preocupação de articular o ensino com a preparação para o exercício profissional ${ }^{(6)}$. Aprovadas as Diretrizes Curriculares Nacionais de Ensino Superior $(\mathrm{DCNs})^{(10)}$, explicita-se a necessidade de reformulações no plano dos processos de ensino e aprendizagem, respeitando a flexibilidade de instalação em âmbito institucional ${ }^{(11)}$.

Em meio a esse quadro de considerações, o estágio passaria a ser valorizado no sentido de proporcionar o exercício de aproximação ao mundo real. Nessa perspectiva, explicita-se a preocupação com a formação de enfermeiros generalistas, ressaltando-se a obrigatoriedade do estágio curricular "nos últimos dois semestres do curso"(10). A propósito, a resolução do $C N E^{(11)}$ enfatiza a formação no atendimento às necessidades de saúde da população, com ênfase no SUS, valorizando a relação entre a teoria e a prática nas ações de saúde coletiva e individual, em hospitais gerais, especializados e unidades básicas de saúde. O cuidado primário em saúde torna-se uma meta a ser contemplada pelo ensino em todos os anos da Graduação, registrando-se o reconhecimento da assistência à prematuridade no âmbito domiciliar.

Tais delineamentos subsidiam a necessidade de analisar o diagnóstico situacional sobre as condições de concretização dos estágios de Neonatologia na Graduação de Enfermagem, a partir da identificação dos desafios educacionais vigentes visando ao seu aprimoramento.

\section{METODOLOGIA}

A realização deste levantamento, em caráter exploratório e com abordagem qualitativa, circunscreveu-se a duas universidades da cidade de São Paulo: uma pública (Uni A), cujo estágio de Neonatologia se insere na área da Pediatria, e outra, 
privada (Uni B), cujo estágio está vinculado a área da Saúde da Mulher.

Considerando a dimensão política do currículo, a investigação comportou, num primeiro plano, a identificação do espaço do estágio no projeto político institucional, a partir de entrevistas com os coordenadores de curso (E1) e docentes (E2), apoiadas na análise documental. Recorrendo-se a análise temática ${ }^{(12)}$, este levantamento levou em conta a história institucional, a inserção do estágio na organização curricular ao lado de Projetos de Reformulação, assim como a consideração de conteúdos e integração teórico-prática.

Num segundo plano, o levantamento contemplou a avaliação dos alunos, a partir do preenchimento de questionários e realização de grupos focais. O questionário, com questões abertas e fechadas, foi distribuído ao universo da turma do $6^{\circ}$ semestre ( $3^{\circ}$ ano) de Graduação, que estava concluindo ou já havia passado pela fase do estágio de Neonatologia. De um total de 59 questionários, retornaram 57. Na Uni B foram distribuídos 40 questionários no final de uma aula de Saúde da Mulher - 21 (53\%) retornaram preenchidos; 6 (15\%) foram desconsiderados pelo fato de os alunos não terem passado pelo campo de estágio. Mesmo considerando o número limitado de respondentes, esse segmento do estudo foi considerado, tendo em vista o caráter exploratório do levantamento, sendo priorizada a dimensão qualitativa do estudo.

Os questionários envolveram a consideração de quatro itens: identificação de conteúdos teóricos ministrados sobre os recém-nascidos normais e de baixo e médio risco, incluindo treinamento em laboratório e as instruções sobre a SAE; caracterização das condições materiais e humanas do cenário de aprendizagem; avaliação da concepção a respeito da formação generalista; e as expectativas dos alunos em relação à formação propiciada pelo estágio e sua adequação ao mercado de trabalho.

Tendo em vista a apreensão da articulação das informações disponibilizadas nos questionários, foram realizados, também, dois grupos focais. Todos os alunos foram convidados a participar dessa atividade, marcada para o dia subsequente à aplicação do questionário. O grupo focal na Uni A foi constituído por seis alunos; na Uni B, por quatro. Os grupos de discussão trabalharam as seguintes questões: $O$ que acharam do estágio de enfermagem em Neonatologia? Suas expectativas foram atendidas no decorrer do estágio? O que aprenderam e o que gostariam de aprender, levando em conta o exercício profissional após a Graduação?

Contando com a presença de um moderador, acompanhado de um observador, o grupo permitiu, numa discussão livre, configurar um panorama de posicionamentos compartilhados sobre o tema em debate, favorecendo a apreensão da questão em sua complexidade. Os dados foram gravados e transcritos, utilizando-se, igualmente, a análise temática ${ }^{(12)}$.

O projeto de pesquisa foi aprovado pelo Comitê de Ética da Unifesp (Protocolo n. 0783/05). A coleta de dados foi precedida pela autorização das instituições. A aplicação dos questionários e a realização do grupo focal envolveram a assinatura prévia do Termo de Consentimento Livre e Esclarecido.

\section{RESULTADOS E DISCUSSÃO}

\section{O estágio na modalidade 1}

O Curso de Enfermagem na Uni A, sob os cuidados de religiosas, foi fundado em 1939, para atender ao Hospital Y. No contexto do desenvolvimento da industrialização, ele incorporava a formação voltada a uma prática moderna, fundamentada nas ciências ${ }^{(11)}$. Estruturado em ciclos, recortados pelas disciplinas, o curso, em 1962, incorpora o aumento da carga horária total, da qual $10 \%$ do tempo era reservado para a realização de estágios, conforme preconizavam as disposições da época ${ }^{(7)}$. Diante da Reforma Universitária em 1970 ${ }^{(5)}$, a Escola passou a atender ao requerimento do currículo mínimo, composto pelos ciclos pré-profissional, profissional e, finalmente, pelas habilitações convencionadas.

Integrando o complexo médico de seu entorno, em 1976 o Curso passou pelo processo de federalização ${ }^{(12)}$, que coincide com a incorporação das práticas administrativas e o exercício da $\mathrm{SAE}^{(11)}$, buscando romper com o distanciamento entre o ensino e a prática.

O contexto marcado pelo crescimento dos cursos de graduação e pós-graduação associado ao desenvolvimento das especializações configura o pano de fundo da inclusão da disciplina de Enfermagem em Saúde Neonatal no currículo da Graduação, constituindo uma marca singular de inserção disciplinar no ensino de enfermagem ${ }^{(13)}$.

Desse modo, a reorganização da assistência ao lado da preocupação na formação de enfermeiras "na prática do cuidar", para além das práticas administrativas, desencadeia a preocupação com a formação generalista na Escola, tendo em vista a capacitação para atuação no âmbito do SUS ${ }^{(14)}$. Constituindo campos próprios de estágio, o ensino se vincula ao hospital, ao lado de convênios com outras instituições, atuando junto ao SUS em regiões como Diadema, Pirajussara e Vila Maria. Segundo o Plano Curricular ${ }^{(15)}$, a Escola assume a prestação de serviços à população, junto ao Estágio Curricular previsto para ocorrer no último ano do curso, sendo mantidos os estágios disciplinares com a denominação práticas clínicas.

$\mathrm{Na}$ vigência do processo de reformas em atenção às DCNs ${ }^{(10)}$, desencadeado a partir de 2004, a Neonatologia, como disciplina autônoma, insere-se na área da Enfermagem Pediátrica. Contando com a presença do aluno em tempo integral, a disciplina comporta uma carga horária de 180 horas, sendo 60 horas para a teoria e 120 horas para a prática ${ }^{(15)}$.

Sem pretender esgotar a constituição da ementa do curso, os conteúdos abordados, segundo a docente entrevistada, incluem "as características anatômicas e fisiológicas do RN a termo e pré-termo, a questão do vínculo RN e família e patologias principais do RN de médio risco". A integração teórico-prática, por sua vez, é resgatada no estágio disciplinar: "nós damos banho em campo, [realizamos] o teste do pezinho, [passamos] sonda nasogástrica e [administramos] medicações". Na falta de RNs para os alunos cuidarem, "o docente busca outros recursos no próprio campo". Uma das possibilidades é a "visita domiciliar às mulheres selecionadas no alojamento conjunto, agendadas após uma semana" da alta. Identificadas as alterações no RN atendido 
no domicílio, o caso é encaminhado para outros níveis de assistência.

Configura-se, nessas condições, o cenário da avaliação do estágio disciplinar na perspectiva dos alunos, em meio ao processo de reorganização curricular. Os alunos entraram em contato com os conteúdos relacionados com o RN normal nas aulas teóricas e no estágio, e, secundariamente, com RNs de baixo e médio risco - coerente com a programação do cur$\mathrm{so}^{(15)}$ - levando em consideração que o alto risco constituiria objeto de ensino após a Graduação.

Quanto ao treinamento prático, os alunos registraram ausência de atuação em laboratórios, valorizado, no dizer deles, pela "oportunidade de aproximação à prática", "aprendizado de técnicas na presença de professores", tendo em vista "evitar acidentes futuros" etc.

Em relação ao estágio, propriamente dito, os alunos referiram que os recursos materiais disponíveis foram suficientes para a aprendizagem. Segundo eles: "o Hospital D é muito organizado, rico em material"; "não havia nenhum material de alta tecnologia, mas também não faltava nada"; "não faltou material e nem medicação", já no [Hospital] VM "faltaram muitos materiais, mas conhecemos outros recursos". Vale frisar a menção ao fato de que "algumas coisas ficavam na teoria" e, segundo alguns, "todos os dias precisávamos improvisar".

Com relação aos recursos humanos - ao lado da valorização da supervisora - a apreciação, de forma geral, foi positiva. Entre aqueles que apontaram problemas, registra-se a referência à situação em que o "número de auxiliares não era suficiente para atender os recém-nascidos". Mesmo constituindo campos de estágios regulares da Universidade, os alunos reconhecem deficiências pontuais. A maioria deles considerou boa a acolhida da equipe. Havia, entretanto, "funcionários mal-humorados" revelando dificuldades relacionadas à recepção dos alunos. Tais comentários sinalizam a necessidade de compatibilizar a lógica do ensino com a lógica dos serviços - a qual não pode ser desconsiderada ${ }^{(16)}$.

Os alunos passaram mais tempo no alojamento conjunto do que no berçário de risco. Entretanto, eles gostariam de ter realizado muitas coisas:

Não vimos nenhum RN de alto risco; se mandarem a gente para o berçário (...) e um dos técnicos de enfermagem solicitar uma punção venosa - porque somos enfermeiros - você não vai saber fazer, porque, no caso de um RN de extremo baixo peso, há dificuldades, e isso a gente não vai conseguir ver [durante o estágio].

A discussão evoluiu, sendo ressaltado que: "Não é o objetivo da Graduação, colocar o aluno em contato com RN de alto risco. Os professores deixaram isso claro". Enfatizando a necessidade de especialização para atuar em hospitais, a aluna refere que, "para um berçário de baixo risco, a gente é capacitado (...), acho que isso é o mais importante".

Os alunos revelaram ter aprendido a sistematizar a assistência para o RN, não somente na teoria, mas, também, no estágio. Algumas alunas referiram a importância do estágio na esfera de suas vivências pessoais: "gostei muito da técnica da mãe canguru"; "eu não terei mais medo" no caso de me deparar com o cuidado de um RN.

Mudando o foco para a formação generalista, os alunos ressaltam que ela "é muito importante, pois o mercado de trabalho pede profissionais versáteis e cuidamos de pessoas e não de doenças". No conjunto das respostas, é reiterada a concepção de que o generalista seria o profissional capaz de atender de tudo um pouco: "acho que temos que ter informação sobre todas as áreas da enfermagem"; "uma formação na qual o aluno tenha conhecimento básico sobre todas as áreas na qual possa atuar". Tais relatos se circunscrevem ao quadro de valorização das especializações e não, propriamente, ao da formação de um profissional generalista, formado para atuar no SUS, em consonância com as disposições das $\mathrm{DCNs}^{(10)}$. Com essa ênfase, um único aluno referiu que: "o enfermeiro deve estar apto a conhecer e reconhecer as patologias mais comuns e frequentes em cada grupo, raça e faixa etária (...) nos níveis primário, secundário e terciário, sabendo ao menos identificar os principais problemas e oferecer o cuidado básico".

Expressando significativa satisfação com o estágio de Neonatologia, os alunos apontaram sugestões tendo em vista seu aprimoramento, expressando os anseios pela atuação especializada da Neonatologia, incluindo a atenção aos casos de risco. Ao lado da menção ao treinamento em laboratório, num eixo distintivo, os alunos reiteraram o aumento da carga horária, vislumbrando "realizar mais procedimentos". A propósito foi sugerida a duração de um mês, pelo menos, tendo em vista vivenciar maiores oportunidades de atuação no campo.

Considerando que o estágio "não contempla as horas que eles gostariam" os alunos acabaram por solicitar "não passar tanto tempo no alojamento conjunto e aumentar o tempo com RNs de risco, ou, ainda, assistir todos os tipos de RNs com acompanhamento da enfermeira local". Nessa linha de argumentação, eles acentuaram que gostariam de estagiar na "UTI, mesmo que não fosse [para] cuidar do RN, mas levantar o caso que existe lá dentro do berçário de alto risco para discutir fora". Nessa linha de elaboração, os estudantes reforçaram o desejo de expandir as "discussões de patologias", em detrimento das vivências realizadas anteriormente no alojamento conjunto, na disciplina Saúde da Mulher ${ }^{(15)}$, o que implicaria o redimensionamento do foco dirigido ao recém-nascido de baixo e médio risco.

Vale registrar que faz parte do universo desses alunos a possibilidade da contratação no mercado de trabalho sem a devida especialização, o que alimenta - em meio à valorização das especializações - os anseios pelas vivências junto aos RNs de risco. Segundo eles, "a qualidade fica comprometida (...) não deveria, mas percebo que [o mercado] comporta [sim]". A propósito uma aluna refere que "apesar de ter tido uma boa formação no estágio, ainda não me considero apta para atuar com o RN".

Reiterando a avaliação satisfatória do estágio, eles apresentaram a sugestão para "melhorar o aproveitamento da SAE" ao lado da reorganização do funcionamento do estágio associada à aproximação aos recém-nascidos de risco.

Enquanto vertente sempre presente nas avaliações, a aspiração à especialização que a Neonatologia comporta alimentada 
pela divisão de conteúdos entre a graduação e a pós-graduação, acaba imprimindo a sensação de não término do estágio na Graduação. Essa tensão contorna o desafio da abrangência das disposições relativas à formação generalista, particularmente em relação à atenção primária, conforme preconizam as Diretrizes Curriculares ${ }^{(10)}$.

\section{O estágio na modalidade 2}

Autorizado em 1997, o curso de Enfermagem da Uni B iniciou suas atividades em $2001^{(17)}$. Se a autorização coincide, historicamente, com a vigência da legislação que estabelecia a necessidade de organização dos campos de estágio ${ }^{(5)}$, o início das atividades do curso em 2001 coincide com o estabelecimento das Diretrizes Curriculares ${ }^{(10)}$, que enfatizavam a reformulação do ensino ao lado da formação do enfermeiro no atendimento às necessidades básicas no SUS. Dessa maneira, o curso de enfermagem da referida Universidade comportaria a preocupação de formar os alunos no modelo da atenção primária em saúde desde o $3^{\circ}$ semestre, particularmente, nas atividades educativas junto à comunidade.

O curso, em período parcial, é oferecido em dois horários, diurno e noturno, atendendo, nessas condições, alunos trabaIhadores. Conforme a ementa do curso ${ }^{(17)}$, a grade curricular se estrutura em módulos temáticos semestrais, tendo por pressuposto a possibilidade de maior integração disciplinar, favorecendo a integração de conhecimentos adquiridos nas ciências básicas com as disciplinas profissionalizantes por parte dos alunos.

De acordo com a docente entrevistada (E2), os conteúdos de Neonatologia ministrados pelos professores se referem à "assistência imediata ao recém-nascido na sala de parto e alojamento conjunto, cuidados com os recém-nascidos durante o banho, curativo do coto umbilical, coleta de exames, troca de fraldas e cuidados em fototerapia".

Sem constituir disciplina autônoma, a parte teórica da Neonatologia é ministrada na disciplina de Saúde da Mulher e da Criança, no $3^{\circ}$ ano. O estágio (3 horas semanais) se circunscreve ao setor de alojamento conjunto vinculado à disciplina "Prática Clínica do Processo de Cuidar da Saúde da Mulher", possibilitando a vivência e a realização da SAE junto a RNs de baixo risco. Referenciando a prioridade ao RN normal, os alunos reconheceram os seguintes conteúdos:

Conhecimento dos parâmetros classificatórios do RN normal; técnicas da recepção do RN ao Centro obstétrico; exames e cuidados; exame físico; cuidados relativos a amamentação; dados antropométricos; curativo do coto umbilical; teste do PKU; banho do RN e vacinação.

Tais conteúdos são pertinentes aos objetivos da assistência de enfermagem ao recém-nascido normal - conforme as diretrizes curriculares dos cursos de enfermagem. Parte dos alunos referiu ter recebido informações sobre o $\mathrm{RN}$ de risco registrando referências sobre os "cuidados com oxigenoterapia para crianças com desconforto respiratório; baixo peso e orientação sobre o uso de incubadoras" também foram abordados - mesmo não estando explicitados nos objetivos da disciplina $^{(17)}$.
De acordo com as respostas apresentadas, eles seriam capazes de distinguir um RN normal do patológico. No dizer deles, "aquela criança que está cianótica pode estar com problema pulmonar ou cardíaco". Porém, é significativa a afirmação: "não tivemos muito conteúdo, mas para a formação generalista a gente sabe um pouquinho de cada coisa (...) cada um vai [se ocupar] posteriormente com o que se identificou mais". Isto é, cada aluno, ao terminar a Graduação, deverá procurar aprimoramento ou especialização.

Registrando a ausência de treinamento em laboratório, os alunos sugeriram sua inclusão no curso tendo em vista a oportunidade de "aplicar a teoria", desenvolver "habilidade para a realização de procedimentos", assim como a "noção da prática".

Com relação aos campos de estágio, os alunos reportaram um quadro de limitações quanto aos recursos materiais: "falta de materiais, como agulhas e luvas". Além das instalações serem "péssimas", o "local era horrível, precário" e "não havia Equipamento de Proteção Individual", circunstanciando em suma, um cenário pouco apropriado para a aprendizagem do aluno.

No plano dos recursos humanos, os alunos referiram a "falta da equipe e da enfermeira no campo de estágio". Essas limitações apontam a dificuldade da estruturação dos espaços de ensino envolvendo o compromisso da instituição que fornece o campo de estágio com a aprendizagem do aluno.

A propósito da limitação de "infraestrutura de recursos materiais e humanos", o grupo focal explicitou a dificuldade de manter os mesmos campos de estágio. Segundo os alunos, "às vezes, de semestre para semestre, o contrato com aquele hospital X é desfeito". A ausência de um campo próprio de estágio configura, segundo a coordenadora (E1), uma condição comprometedora na organização dos cenários de práticas. Em meio à afirmação das dificuldades de estabelecer parcerias com os serviços, ganham consistência as referências relativas à precariedade dos recursos materiais e humanos dos campos de estágio no dizer dos alunos.

Os alunos referiram que a "supervisora [era] excelente, atualizada"; "(...) demonstrou na prática o que havia dado em sala de aula". Ela "cobrava muito do grupo, o que nos levava a buscar o conteúdo", ao mesmo tempo que "se mostrou sempre disponível para tirar dúvidas e discutir casos".

Não sendo consensuais as respostas relativas ao ensino e a prática na realização da $\mathrm{SAE}$, alguns alunos mencionaram que não tiveram tal oportunidade porque "não havia sistematização" no campo de estágio. Tal consideração poderia ser relativizada diante da falta de estrutura para o exercício, particularmente, no ambiente hospitalar dos campos de estágios frequentados pelos alunos. Sendo a SAE um instrumento de operacionalização dos cuidados de enfermagem voltado às necessidades básicas de saúde da população, esses resultados reafirmaram as condições, ainda limitadas, de incorporação da SAE no âmbito da abrangência do SUS.

Os alunos associam a formação generalista à concepção de um conhecimento geral, envolvendo treinamento em diferentes clínicas hospitalares. Essa é “a formação que deveria nos proporcionar treinamento de todas as áreas médicas, incluindo prática clínica, não somente teórica". Sem perder de vista 
a especialização, é sugestiva a afirmação de que "é necessário conhecer um pouco de tudo, dando base para escolher uma especialidade". Nessa perspectiva se enquadra a opinião de que "o graduando acaba perdendo informação importante (...) o ensino fica fraco e com algumas falhas".

Apontando para o requisito de um treinamento para além do espaço hospitalar, a concepção generalista aparece associada à ideia de que todo o estágio deve abranger todos os níveis [de atenção] para que melhor se desenvolva o pensamento crítico/científico e a tomada de decisão"; (...) "quando nos formarmos iremos trabalhar com neonatos em ambulatórios" - conforme preconizam as Diretrizes Curriculares a propósito do SUS ${ }^{(10)}$. Como contrapartida dessas disposições, entretanto, registra-se o reconhecimento da incorporação do enfermeiro generalista na área de Neonatologia no mercado de trabalho imediatamente após a formatura. Sem a devida especialização, tal fato constitui uma ameaça sempre presente no universo dos alunos. Realimentando a preocupação com a especialização, eles afirmam que "não se sentem preparados para atuar nestas situações de trabalho - ainda não me sinto uma profissional capaz de assumir um cargo desse"; daí a necessidade reiterada de fazer pós-graduação.

De forma geral, os alunos demonstraram satisfação em relação ao estágio, o que não exclui referências a restrições. Convidados a explicitar essas limitações, eles chamaram a atenção para o pouquíssimo tempo de permanência nos campos de estágio. Além de (re)atualizar a questão da resistência dos funcionários em aceitar os estagiários ao lado das deficiências materiais, certamente contingenciadas pela ausência de campo próprio de estágio, eles fizeram referências à questão da descontinuidade da assistência: "a gente prestava assistência para uma mulher com o seu RN; na outra semana, quando a gente voltava, ela não estava mais ali". Tal quadro, segundo eles, concorre para o aumento da insegurança para "fazer procedimentos com bebês". Nesse contexto se inscreve a sugestão do aumento da carga horária, com vistas à ampliação do treinamento em berçário, e não somente em alojamento conjunto. Os alunos contavam com a oportunidade no estágio da disciplina Saúde da Criança - o que não ocorreu. “Em Saúde da Criança a gente não teve um estágio no hospital; em saúde da criança, o estágio foi numa creche (...) então, a gente viu apenas crianças saudáveis, não tivemos contato com criança com problemas".

Essa colocação revela que os Cursos de Graduação em Enfermagem, ao escolher seus campos de práticas, devem conhecer quais são os recursos de aprendizagem oferecidos pelas instituições concedentes de estágio que corroboram efetivamente a formação do enfermeiro generalista. Nesse caso, os cenários de práticas devem proporcionar aos acadêmicos de enfermagem o acesso às principais áreas básicas, como a Pediatria, garantindo aos futuros egressos a competência de identificar, classificar os principais agravos à saúde da criança e encaminhar crianças de risco para outros níveis de assistência, de forma a proporcionar esse contato do aluno durante a Graduação.

É válido ressaltar que o cenário da creche, assim mencionado pelo aluno anteriormente, estimula o aprendizado da prevenção e promoção à saúde, mas não garante a experiência no trato com crianças doentes na qual o acadêmico possa apreender os cuidados específicos que retratam o universo da atenção secundária e terciária, elementos estes que também compõem a formação generalista do enfermeiro.

Essa aspiração se expressa, ainda, nas respostas às projeções sobre o que gostariam de aprender durante o estágio de Neonatologia. Nessa situação, os alunos responderam: "não tivemos a teoria sobre a Neonatologia". Eles reconhecem que "saberia[m] dizer [algo] sobre os cuidados com o recém-nascido normal, mas nada com muito enfoque no RN de risco" - expressando desencanto em relação à lacuna de uma vivência no espaço hospitalar que implica a valorização, tradicionalmente adstrita ao campo da Neonatologia.

As críticas, nesse sentido, confundem-se, de um lado, com a aspiração relativa à oportunidade de vivências na atuação junto aos RNs alimentada, de certa forma, pela divisão dos conteúdos que se estabelece entre a Graduação e a especialização. De outro, elas se reportam à incompatibilidade dessa diretriz com os requerimentos do mercado de trabalho. Num contexto de expansão da rede assistencial sob o SUS, observa-se a incorporação de egressos da Graduação nos serviços hospitalares, mesmo na ausência da especialização. Nesse caso, o aluno se defronta, literalmente, com uma realidade para a qual não foi preparado(18).

Vale dizer, ainda, que, ao lado da restrição da Graduação ao RN normal, não é dimensionado o tratamento do RN de risco no âmbito da atenção primária, o que acaba por sustentar a desvalorização do ensino fora do espaço hospitalar, retroalimentando a desconsideração da formação generalista, contemplada nos objetivos de ensino da instituição, ou seja, a formação do enfermeiro, que deveria ser pautada nas ações de promoção, prevenção, recuperação e reabilitação da saúde na perspectiva da integralidade da assistência, não está sendo alcançada segundo os relatos supracitados. Nesse espaço de tensão, situa-se o desafio a ser enfrentado pela instituição no cumprimento das $\mathrm{DCNs}^{(10)}$ - somado às dificuldades de compor cenários condizentes de estágio.

\section{CONSIDERAÇÕES FINAIS}

As instituições investigadas, em que pese os distintos contextos de sua emergência, estão sintonizadas, formalmente, com as recomendações das Diretrizes Curriculares. No que tange ao estágio de Neonatologia, os conteúdos são ministrados e se concentram na assistência aos RNs normais, sendo abordadas, secundariamente, questões relacionadas aos RNs de baixo e médio risco - resguardada a convenção de que a assistência ao RN de risco seria atribuição da pós-graduação. Reafirmando a formação generalista, que inscreve o esforço da aproximação à atuação junto à comunidade, preservam-se, entretanto, as marcas da estrutura disciplinar tradicional, com a respectiva vocação especializante.

Se a constituição de uma disciplina autônoma de Neonatologia ampara a estruturação do estágio, também é certo que essa condição não seria uma exigência indispensável diante da recomendação relativa à transversalidade dos temas, num quadro curricular renovado. Dispor, ou não, de campo 
próprio de estágio, entretanto, constitui um diferencial significativo quanto às condições de desenvolvimento do estágio de Neonatologia.

Resguardada a valorização da atuação das supervisoras de estágio, a compatibilização da lógica do ensino e dos serviços continua a constituir um desafio sempre renovado; a questão se apresenta mais grave, entretanto, nas instituições que não contam com campo próprio de estágio. Essa lacuna incidiu não só em relação às condições materiais dos cenários de práticas, mas em relação à recepção dos alunos.

A concepção a respeito da formação generalista, associada à ideia de conhecer de tudo um pouco, condiz, na verdade, com a valorização da formação especializada, potencializada pelas fronteiras convencionadas entre a graduação e a pós-graduação. Manifestando a sensação de uma formação inconclusa, os alunos aspiram por mais atuação junto aos recém-nascidos de risco. Nesse sentido se inscreve a reivindicação de aumento da carga horária de estágio. Ao lado da generalizada insegurança que precede à entrada no mercado de trabalho, vale dizer que esses alunos se defrontam com a ameaça concreta da possibilidade de serem incorporados ao mercado de trabalho, sem a devida especialização, logo após a Graduação.

Sem pretender apontar caminhos para a superação dessa complexa problemática, é certo afirmar que se impõe a revisão da concepção generalista sobre a qual se assenta o ensino - o que implica problematizar não só a dimensão das políticas subjacentes à implantação do SUS, como a própria centralidade da prática como eixo ordenador do ensino, para efeito da (re)formatação do currículo. Se a especialização demarca a lógica do ensino voltada ao RN de risco no âmbito da atenção terciária ou quaternária - ficando a atenção ao RN sadio restrita à Graduação - as novas disposições exigiriam repensar esses limites, considerando que os problemas relacionados aos RNs de risco também comportariam atuações no âmbito da atenção primária e secundária.

\section{REFERÊNCIAS}

1. Maltagliati LA, Goldenberg P. Reforma curricular e pesquisa na graduação em odontologia: uma história em construção. Hist Ciênc Saúde-Manguinhos 2007;14(1):1329-40.

2. Brasil. Lei n. 4.024, de 20 de dezembro de 1961. Lei de Diretrizes e Bases da Educação Nacional. Diário Oficial da União 27 dez 1961.

3. Santos SSC. Currículos de enfermagem do Brasil e as diretrizes - novas perspectivas. Rev Bras Enferm 2003;56(4):361-4.

4. Goldenberg P. Repensando a desnutrição como questão social. 2. ed. São Paulo: Cortez; 1989.

5. Santos I (Org). Enfermagem fundamental. Realidade, questões, soluções. São Paulo: Atheneu; 2001.

6. Nascimento ES. Formação por competência do enfermeiro: alternância teórica-prática, profissionalização e pensamento complexo. Rev Bras Enferm 2003;56(4):365-8.

7. Ramos FRS. Acerca de diretrizes curriculares e projetos pedagógicos: um início de reflexão. Rev Bras Enferm 2003;56(4):340-2.

8. Feuerwerker LCM. Processos de mudança na graduação de medicina. In: Marins JJN (Org.). Educação médica em transformação. São Paulo: Hucitec; 2004. p. 47-82.

9. Brasil. Lei n. 9.394, de 20 de dezembro de 1996. Dispõe sobre as Diretrizes e bases da Educação Nacional. Diário Oficial da União 23 dez 1996.

10. Ministério da Educação e Cultura (Brasil) Resolução CNE/
CES n. 3 de 2001. Institui as Diretrizes Curriculares Nacionais do curso de graduação em Enfermagem. Diário Oficial da União 9 nov 2001.

11. Medeiros M, Tipple AFV, Munari DB. A expansão das escolas de enfermagem no Brasil na primeira metade do século XX. Rev Eletrônica Enferm [periódicos na internet]. 1999 [acesso em 17 jan 2006];10(1) Disponível em: http://www.fen.ufg.br/revista.

12. Minayo MCS. O desafio do conhecimento: pesquisa qualitativa em saúde. 6. ed. São Paulo: Hucitec; 2004.

13. Naganuma M. Enfermagem neonatológica - conhecimento, prática e percepção de alunos de graduação em Enfermagem. São Paulo. Tese [Doutorado em Enfermagem] - Universidade Federal de São Paulo; 1993.

14. Vianna LAC. Enfermagem: da vida abnegada à autodeterminação profissional. Acta Paul Enferm 2000; 13(n. esp.):17-26.

15. Universidade Federal de São Paulo. Projeto Político Pedagógico do curso de Enfermagem. São Paulo: Unifesp; 2004.

16. Friedländer MR. Como supervisionar um estágio de Enfermagem. São Paulo: Green Forest do Brasil; 2005.

17. Universidade Paulista. Projeto Político Pedagógico do curso de Enfermagem. São Paulo: Unip; 2005.

18. Toma E. UTI neonatal - assistência humanizada ao recém-nascido. Rev do Conselho Regional de Enferm 2004;9(1):2-4. 